\title{
Comparison of Anti CCP Positivity in RA and Other Arthritic Patients Including Connective Tissue Disorders
}

\author{
D. Ayisha*, Eunice Swarna Jacob and P. Shanmugapriya
}

Department of Microbiology, Thanjavur Medical College, Thanjavur, Tamil Nadu, India

*Corresponding author

A B S T R A C T

Rheumatoid Arthritis (RA) is the most common systemic inflammatory, Auto immune Rheumatic disease of unknown etiology. Although the precise aetiology of RA remains

Keywords unknown, there is strong evidence for autoimmunity, The present study is to evaluate the significance of AntiCCP antibodies in Rheumatoid Arthritis and to compare it with other Connective Tissue Disorders (CTD including SLE, and Osteo Arthritis (OA) and in

Anti CCP positivity, Arthritic patients, Healthy Blood Donors as Control. From January 2016 to December 2016 a total number of 200 (each group50) subjects including both males and females were studied. Anti-CCP was positive in 39 of 50 RA patients (78\%), 2 of 50 (4\%) CTD (SLE) cases and none were positive among(50) OA and (50) HBD, Sensitivity and Specificity of AntiCCP test was $78 \%$ \& $98.6 \%$ respectively and RF test results were positive in 38 of 50 RA patients (76\%) 11 of $50(22 \%)$ - CTD including SLE patients, 6 of $50(12 \%)$ - OA patients and 4 of 50 (8\%) - of HBD. Sensitivity and Specificity of RF test in RA was $76 \%$ and $86 \%$ respectively. In conclusion, based upon the higher sensitivity and specificity of the Anti CCP test in RA than other Connective Tissue Disorders including SLE, shows its significant association with RA. Thus it helps in distinguishing RA from other erosive disorders and excluding them from RA.

\section{Introduction}

Rheumatoid Arthritis (RA) is the most common systemic inflammatory, auto immune Rheumatic disease of unknown etiology $y^{1,2,3,4}$ affecting nearly $1 \%{ }^{1,3,5,6,7,8.9,10}$ of the adult population worldwide. Although the precise aetiology of RA remains unknown ${ }^{1}$, there is strong evidence for autoimmunity, since several auto antibodies are associated with the disease ${ }^{6}$.

The potential of the synovial inflammation to cause cartilage damage and bone erosions and subsequent changes in joint integrity is the hallmark of the disease. The disease occurs frequently in women than in men $(2.5-3: 1)$. The disease can begin at any age, peak onset typically occurs in the fourth and fifth decades of life. ${ }^{7}$ Genetic studies have demonstrated that a genetic predisposition resides in the HLA-DR locus. ${ }^{7,12}$ For decades, RA is diagnosed primarily according to clinical manifestations based upon ACR criteria $^{3,5,7,14,15}$, in which the only serological marker is RF test. Rheumatoid factor (RF) is an antibody directed against the $\mathrm{Fc}$ region of IgG that has been used as a diagnostic marker for Rheumatoid Arthritis. ${ }^{2,3,6,7,16}$ and is recommended as a screening test ${ }^{3}$ and can be 
detected in up to $80 \%$ of RA patients ${ }^{6,17}$ However it is nonspecific ${ }^{16}$ and may be present in $5-10 \%$ of healthy elderly persons or in patients with other autoimmune and infectious diseases ${ }^{2,6,11}$.

So it is therefore crucial to have a reliable and specific test to identify the RA. ${ }^{17}$ The other most specific auto antibody system for RA is the family of auto antibodies directed to Citrulline-containing proteins, including antiperinuclear factor (APF) in $1964^{7}$, antikeratin antibodies (AKA) in 1979, ${ }^{7}$ antifilaggrin antibodies (AFA) and anti-Sa ${ }^{3,7,11}$. Because of rigorous technical requirements for their detection, they have never been widely used as markers despite their high specificity ${ }^{3,6}$.

Recently, a new serological test (biological marker $)^{20}$ the anti-Cyclic Citrullinated Peptide(anti-CCP) ${ }^{2,20}$ was developed ${ }^{6 .}$

Citrulline is formed by deamination of arginine residues in several proteins by the action of enzyme peptidyl arginine deiminase (PAD) ${ }^{6,7,16,21,20}$ which is present abundantly in inflammatory synovium \& proteins such as fibrin $^{6,7}$. Citrullinated extracellular fibrin in the RA synovium may be one of the major autoantigens driving local immune response suggested by the discovery of local production anti- CCP antibodies in the joint.

The high specificity of anti-CCP in patients with RA can exclude other rheumatic or immune diseases, ${ }^{6,7,9}$ (like SLE \& OA). So it is useful in diagnosis as well as exclusion of RA. ${ }^{24 . .}$ Hence the study.

\section{Materials and Methods}

\section{Study design}

This is a combined Cross Sectional \& Case Control study

\section{Study subjects}

The total numbers of subjects in this study for evaluation were 200, which included both male and female patients who attended the Out Patient Clinics at the Rheumatology and Orthopaedics Department and Healthy Blood Donors who attended the Blood bank, Thanjavur Medical College Hospital, Thanjavur. This study period extended from January 2016 to December 2016

The study subjects, in both genders were divided into four groups. Each group include 50 patients.

Three groups (Rheumatoid Arthritis (RA), Connective Tissue Disorders including Systemic Lupus Erythematosus (SLE), Osteo Arthritis (OA) are based upon the clinical and fourth group is healthy individuals (blood donors) as control conditions (inclusion and exclusion criteria's in annexure).

\section{Sample}

$3-5 \mathrm{ml}$ of Venous Blood was collected aseptically, Serum was separated and stored at $2-8^{0} \mathrm{c}$, if delay at $-20{ }^{0} \mathrm{C}$.

\section{RF Test -Rheumatoid Factor ${ }^{14}$}

Method of Detection: Serological test by the latex agglutination ${ }^{\mathbf{1 5}}$ slide test.

\section{Principle}

Human globulin $\mathrm{IgG}$ is coated with latex particles. Serum was mixed with latex reagent. Agglutination appears if the sample is positive for Rheumatoid factor. Negative if no agglutination appears and remains as smooth suspension. (Latex coated with $\mathrm{IgG}+$ serum $=$ IgG antibody binds with IgG \& cause latex particles to flocculate.) It is a rapid qualitative slide test. 
Also tested both Positive control \&Negative control

\section{Interpretation of results}

Distinct agglutination indicates RF content > than $20 \mathrm{IU} \mathrm{RF} / \mathrm{ml}$-undiluted serum.

\section{Anti CCP test}

Anti-CCP antibody was detected by ELISA technique. ${ }^{11}$ by using GENESIS CPA (citrullinated protein antibodies) ELISA kit for detection of Rheumatoid arthritis specific $\operatorname{IgG}$ antibodies to citrullinated protein.

Sample serum.storage- $2-8^{0} \mathrm{c} /-20^{\circ} \mathrm{c}$

Test done as per kit instruction as a multistep procedure and took readings of the optical density of each well by using Microplate Reader within 10 minutes. (620nm reference filter is used.)

\section{Results}

Samples with OD $\geq$ OD (optical density) of $6.25 \mathrm{U} / \mathrm{ml}$ Standard are positive.

Samples with OD $\leq$ OD (optical density) of $6.25 \mathrm{U} / \mathrm{ml}$ Standard are Negative. The results obtained were tabulated and analyzed.

\section{Results and Discussion}

In the present study carried out on patients having various arthritic diseases,

\section{Age wise distribution}

In RA was more in the age group of 50-60yrs, in SLE in 30-50yrs in OA in 40-50yrs.

\section{Sex wise distribution}

$\mathrm{M} / \mathrm{F}$ ratio $-\mathrm{RA}-1: 2.33$, CTD- $1: 2.12, \mathrm{OA}-$ $1: 2.84$.
Age/sex distribution of various arthritic diseases male were affected $<$ than female

\section{Anti-CCP}

It was positive in 39 of 50 (78\%) RA patients, 2 of 50 (4\%) CTD (SLE) cases, and none were positive among (50) OA and (50) HBD.

\section{RF test}

Positive in 38 of 50(76\%) RA patients, 11 of 50 (22\%) - CTD including SLE patients, 6 of $50(12 \%)$ - OA patients and 4 of $50(8 \%)$ - of HBD (Table 3).

\section{Sensitivity and specificity of RF test}

For R A (RF Positive in RA -38, NON RA 17) was $76 \%$ and $86 \%$ respectively (Table 2 ).

\section{Sensitivity and specificity for Anti CCP test}

For RA was $78 \%$ and $98.6 \%$ respectively (Table 2)

Sensitivity, specificity, PPV and NPV of Anti CCP and RF tests in RA

Sensitivity, Specificity, PPV \& NPV of

Anti CCP - 78\%, 98.6\%, 95.1\% \& 93\%

RF - $76 \%, 86 \%, 64.4 \% \& 91.4 \%$.

Anti CCP \& RF - 66\%, 98.6\%, $94.2 \%$ \& $89.7 \%$.

ANTI CCP / RF - 88\%, 86\%, 67.7\% \& 95.5.\%.

RA is associated with only a few specific auto antibodies, including APF, AKA and antiCCP and several less specific auto antibodies including $\mathrm{RF}^{4}$. Despite a well-documented lack of specificity, RF continues to be a serological test for RA because of its 
inclusion in ACR criteria. However to date no single autoantibody has demonstrated adequate positive diagnostic value to form the basis of clinical decisions. So auto antibodies present in RA, connective tissue disorders including SLE and OA have been evaluated in the present study, mainly for their diagnostic value, and to differentiate various arthritic diseases.

In recent research by Schellekens $\mathrm{GA},{ }^{17}$ he has observed the diagnostic significance of a novel RA specific autoantibody, determined by ELISA using synthetic peptides containing citrulline.

In this present study Anti CCP test results suggest the significance of anti CCP positivity in diagnosis of RA and differentiating RA from other arthritis. To minimize the errors patients were selected according to the inclusion criteria's. Of all the above different Rheumatological diseases (SLE and OA), Anti CCP was more sensitive and more specific for RA, whereas RF was almost equally sensitive but less specific than Anti CCP for RA, because it is positive in other arthritic diseases and healthy persons also (Table 4 and 5).

\section{Age/Sex distribution of various Arthritic diseases}

Age

The incidence of all types of arthritis is very low in age group of 20-30 years.

\section{Sex}

M/F ratio - Males are less affected than the females in all arthritic diseases.

\section{Sensitivity of RF in RA}

On analyzing the sensitivity of RF, the present study shows $76 \%$ sensitivity in RA patients. This goes in parallel with the study by Lee and Schur et al., ${ }^{24}$ who found a sensitivity of $71.6 \%$ for RF.

But in the studies by Munevver Serdaroflu et al., ${ }^{25,}$ 65\% sensitivity, Sibel Altun et al., ${ }^{5}$ $60 \%$ sensitivity, Machold et al., ${ }^{19}$ 55\% sensitivity, Nehir Samanci et al., ${ }^{11} 44.8 \%$. Sensitivity for RF was higher in the present study than the previous studies. This discrepancy may be due to method of selection of cases, and type of kits used for testing.

In contrast a study by Dubucquoi et al., ${ }^{24}$ showed 94\% sensitivity for RF which is higher than the present study. The controversy may be due to low sample size, and short period of study.

\section{Specificity of RF}

In the present study specificity of RF was $86 \%$, which is in consistent with the study by Sibel Altun et al., ${ }^{5}$ which showed the specificity of RF as $86.4 \%$. But a study by Lee and Schur $^{24}$ observed specificity of $80.3 \%$ which is lower than the present study. But in Dubucquoi et al., ${ }^{24}$ study the specificity of RF was $53 \%$ only. The indifference may be due to small sample size because the study was carried out as a cross sectional study which included different groups, and also may be due to short duration of study

\section{Specificity for Anti-CCP}

In the present study specificity for anti-CCP is $98.6 \%$, which is similar to the study by Sibel Altun et al., ${ }^{5 .}$ with $98.6 \%$. The present study goes in parallel with the previous studies by Bizzaro et al., ${ }^{5} \&$ Gerard A. Schellekens et al., ${ }^{8}$ both showing 98 , and Dmitry Karayev et al., ${ }^{39}$ 97\%. Lee and Schur ${ }^{24}$ observed 90\%. But the studies by Nehir Samanci et al., ${ }^{11} 99 \%$, and Münevver Serdaroflu et al., ${ }^{25} 100 \%$ 
which was higher than the present study. This discrepancy may be due to sample selection criteria's and type of kits used for testing.

\section{Sensitivity of both RF and Anti CCP antibody}

In the present study both RF and Anti-CCP are positive in $(66 \%)$ RA patients. The results are comparable with the study by Sibel Altun et al., ${ }^{5}-59.3 \%$ positivity. This value is higher than the study by Schellekens et al., ${ }^{5}$ (39\%) In contrast a study by Dmitry Karayev et al., ${ }^{39}$ showed $99.6 \%$ sensitivity.

This may be due to prompt selection of cases in the present study and using advanced type of kit.

Table.1 Anti-CCP \& RF results in various arthritic diseases \& HBD

\begin{tabular}{|c|c|c|}
\hline CATEGORY & Anti CCP Positivity & RF Positivity \\
\hline RA (50) & $39(78 \%)$ & $38(76 \%)$ \\
\hline CTD (50) & $2(4 \%)$ & $11(22 \%)$ \\
\hline OA (50) & 0 & $6(12 \%)$ \\
\hline HBD (50) & 0 & $4(8 \%)$ \\
\hline
\end{tabular}

Table.2 Sensitivity and specificity of RF Test in RA

\begin{tabular}{|c|c|c|c|}
\hline RF & Positive & Negative & Total \\
\hline RA(50) & 38 & 12 & 50 \\
\hline Non RA (150) SLE+ OA + HBD & 21 & 129 & 150 \\
\hline Total & 59 & 141 & 200 \\
\hline
\end{tabular}

Sensitivity $76 \%$, Specificity $86 \%$

Table.3 Sensitivity and specificity of Anti CCP Test in RA

\begin{tabular}{|c|c|c|c|}
\hline TEST & Anti ccp Positive & Anti ccp Negative & Total \\
\hline RA(50) & 39 & 11 & 50 \\
\hline Non RA(150) SLE+ OA + HBD & 2 & 148 & 150 \\
\hline Total & 41 & 159 & 200 \\
\hline
\end{tabular}

Sensitivity: $78 \%$, Specificity: $98.6 \%$

Table.4 Positivity of anti CCP and /or RF on the groups

\begin{tabular}{|l|c|c|c|c|}
\hline & $\begin{array}{c}\text { In RA patients } \\
\mathrm{n}=(50)\end{array}$ & $\begin{array}{c}\text { SLE } \\
\mathrm{n}=50\end{array}$ & $\begin{array}{c}\text { OA } \\
\mathrm{n}=50\end{array}$ & $\begin{array}{c}\text { Control groups } \\
\text { (HBD) } \mathrm{n}=50\end{array}$ \\
\hline Anti CCP positive & 39 & 2 & 0 & 0 \\
\hline RF positive & $33(66 \%)$ & $2(4 \%)$ & 0 & 0 \\
\hline RF negative & $6(12 \%)$ & 0 & 0 & 0 \\
\hline & & & & 50 \\
\hline Anti CCP negative & 11 & 48 & 50 & $4(8 \%)$ \\
\hline RF positive & $5(10 \%)$ & $9(18 \%)$ & $6(12 \%)$ & $46(92 \%)$ \\
\hline RF negative & $6(12 \%)$ & $39(78 \%)$ & $44(88 \%)$ & \\
\hline
\end{tabular}


Table.5 Sensitivity, specificity, PPV and NPV of anti CCP and RF tests

\begin{tabular}{|c|c|c|c|c|}
\hline Tests & Sensitivity \% & Specificity \% & PPVTest \% & NPV test \% \\
\hline Anti CCP & 78 & 98.6 & 95.1 & 93 \\
\hline RF & 76 & 86 & 64.4 & 91.4 \\
\hline ANTI CCP \& RF & 66 & 98.6 & 94.2 & 89.7 \\
\hline ANTICCP / RF & 88 & 86 & 67.7 & 95.5 \\
\hline
\end{tabular}

Chart.1 Anti-CCP\& RF test results in all arthritic groups and HBD

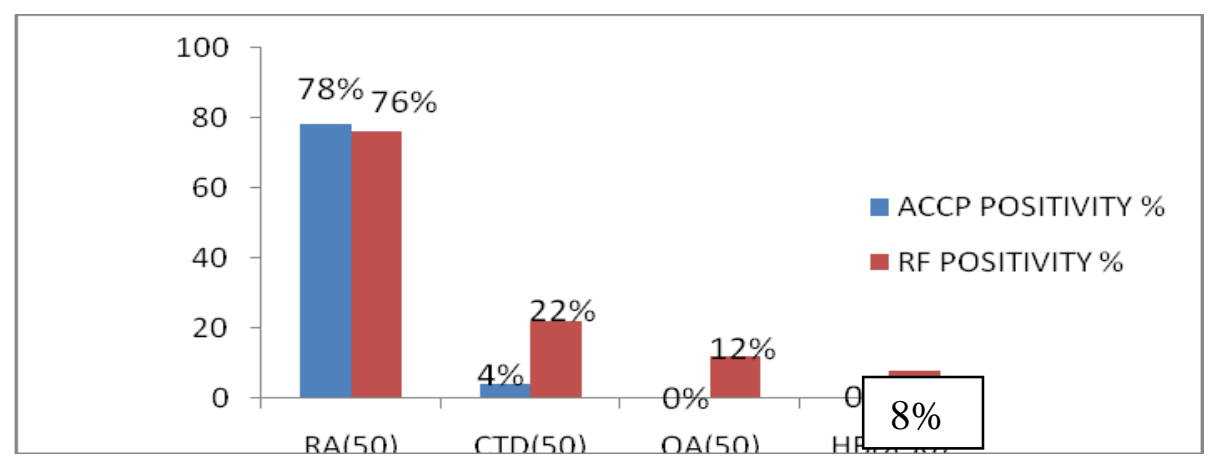

Chart.2 Sensitivity and specificity of RF Test in RA

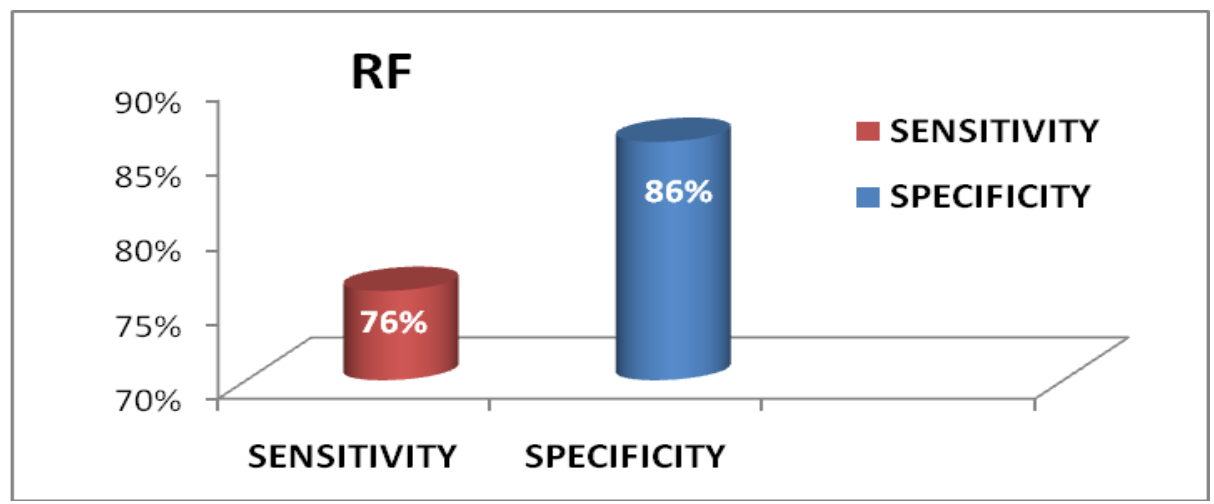

Chart.3 Sensitivity and specificity of anti CCP Test in RA

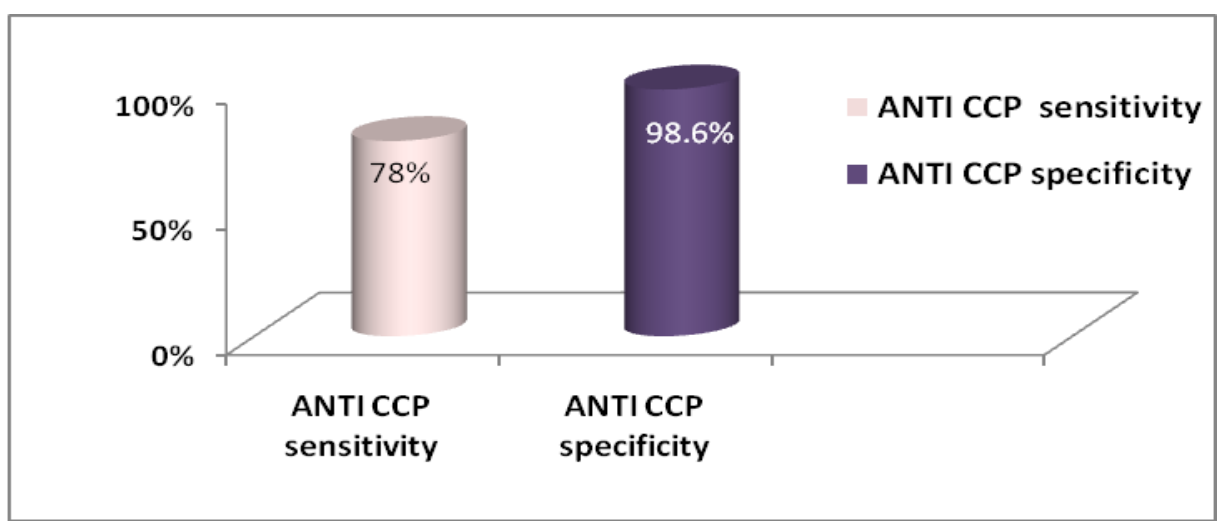


Chart.4 Distribution of positivities of Anti CCP and /or RF on the groups

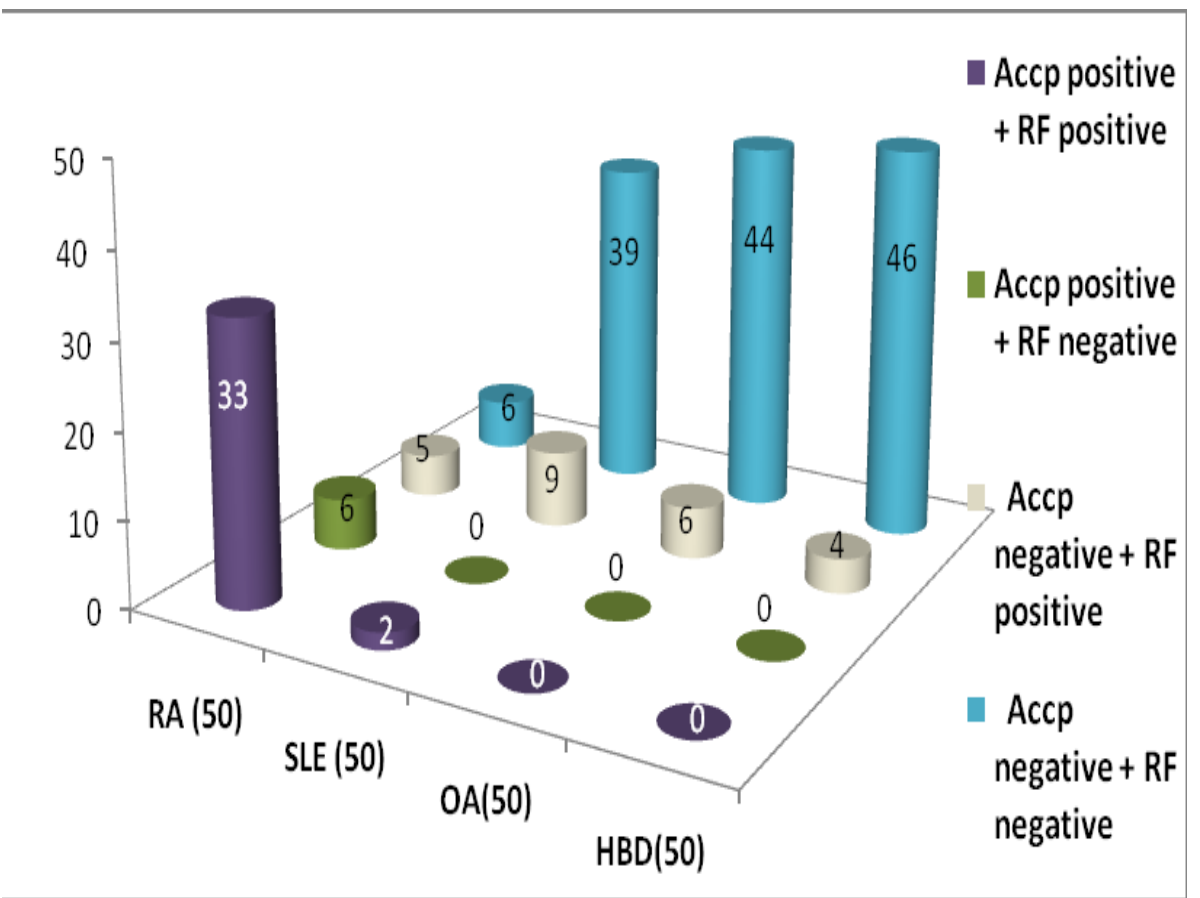

Chart.5 Sensitivity, specificity, PPV and NPV of Anti CCP and RF tests

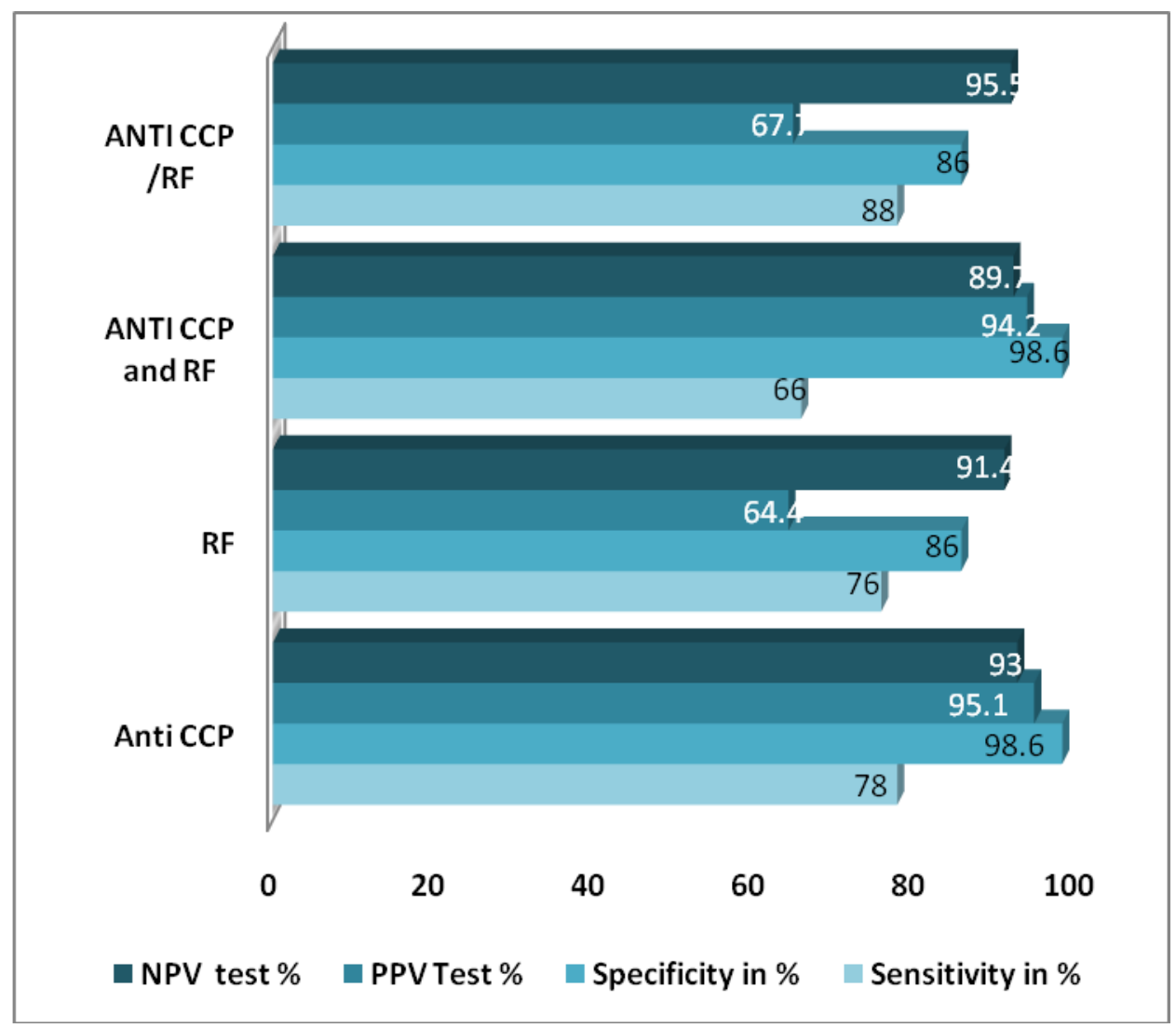


Colour Plate.1 RA test kit with reagents

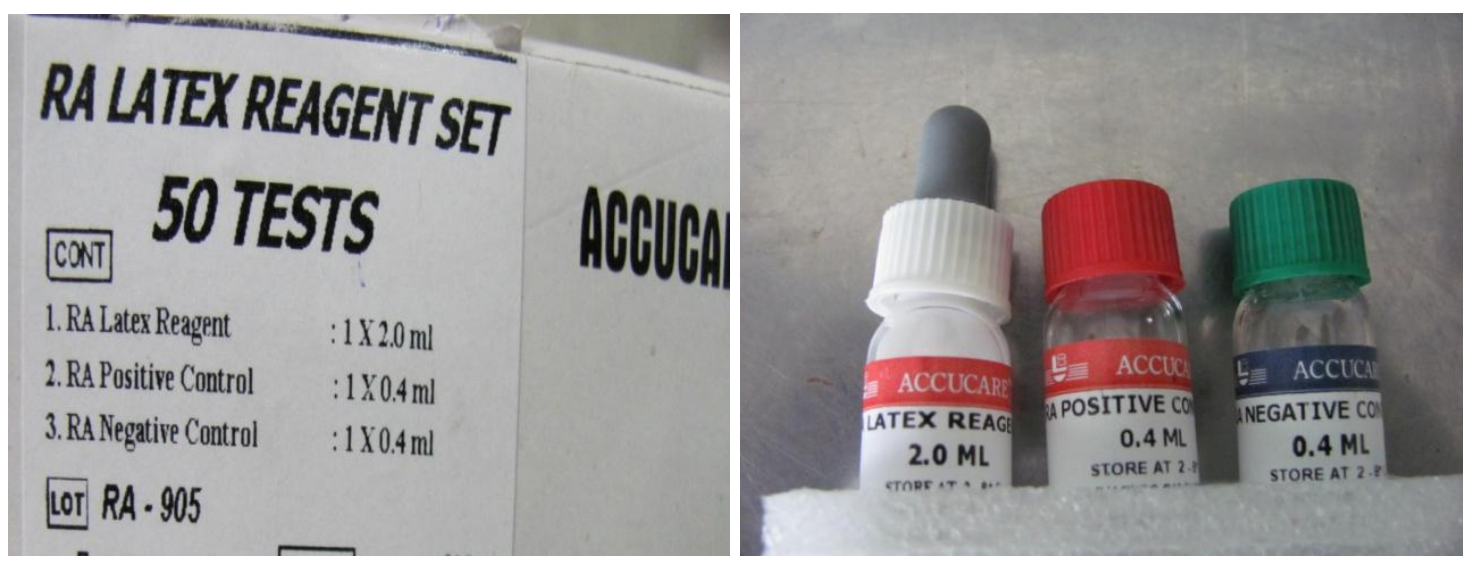

Colour Plate.2 RA test result

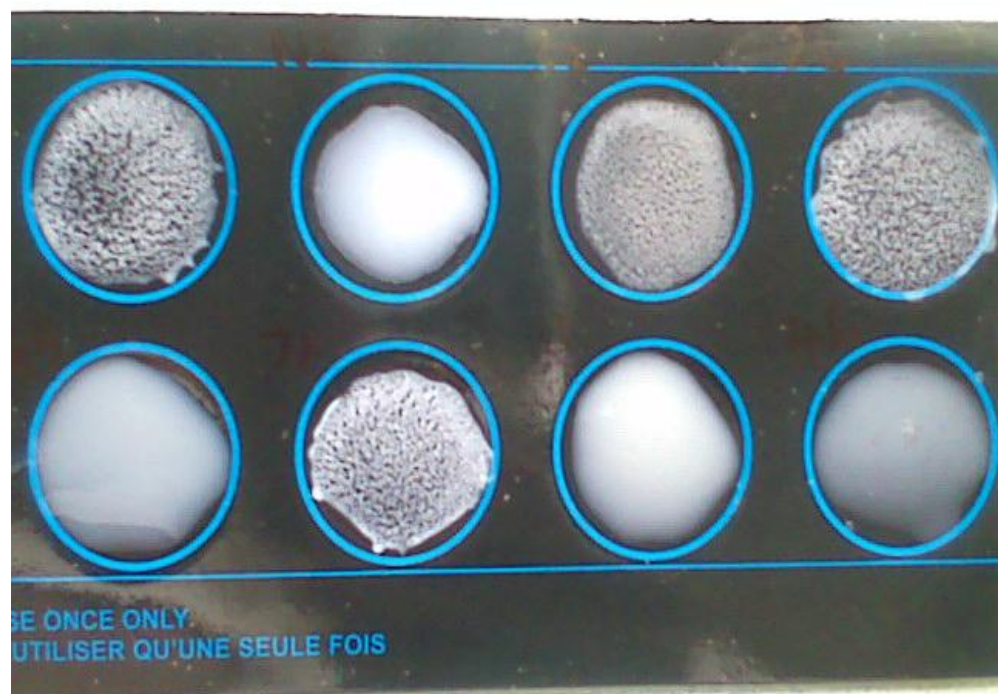

Colour Plate.3 Anti CCP Test Kit Colour Plate.4 Anti CCP Test Reagents
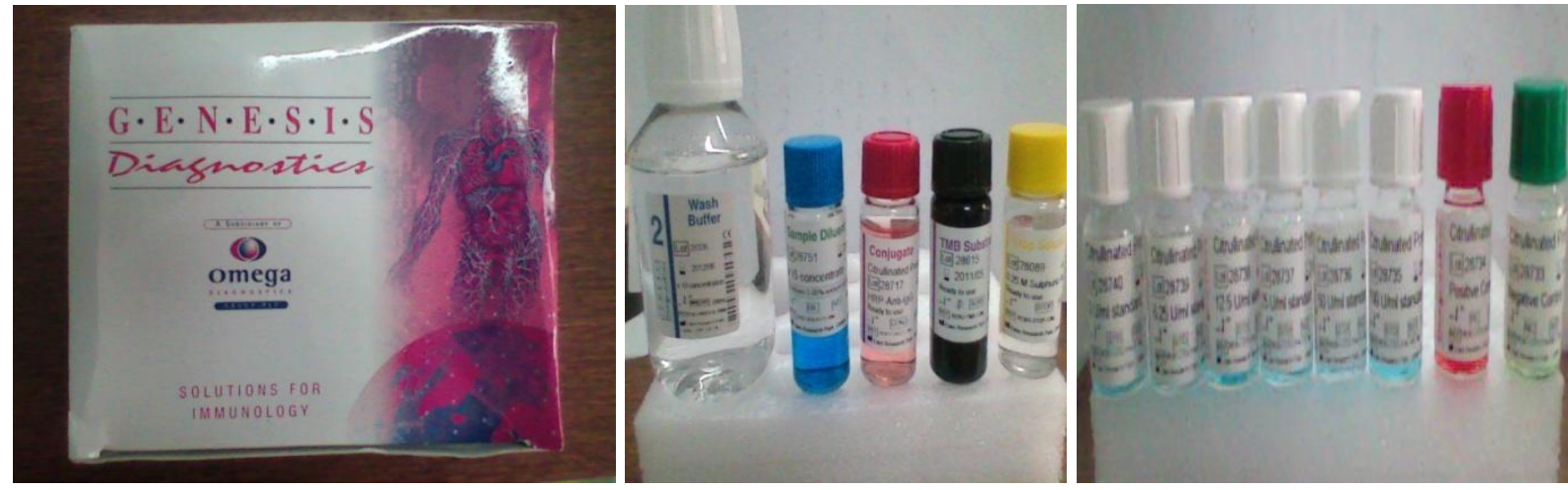


\section{Colour Plate.5 Anti CCP Test Procedure}

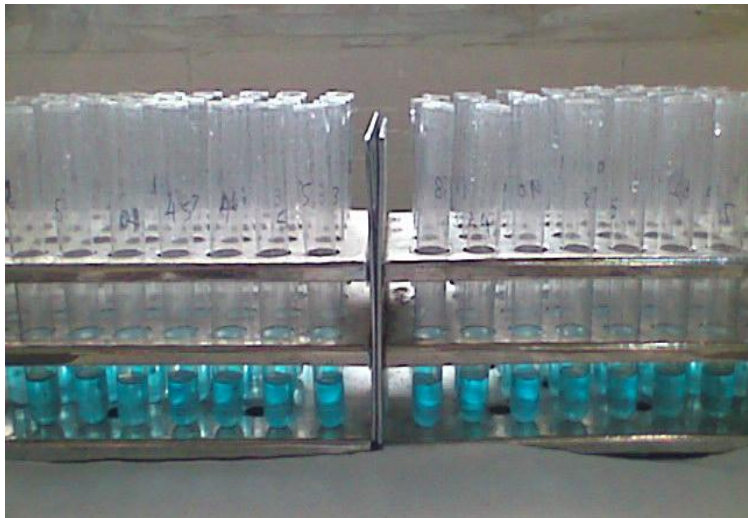

5a. Diluted Samples

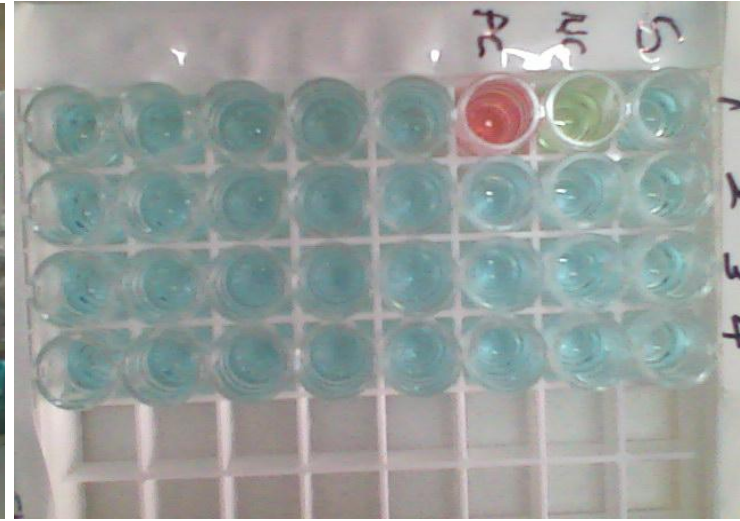

5b. Test Procedure

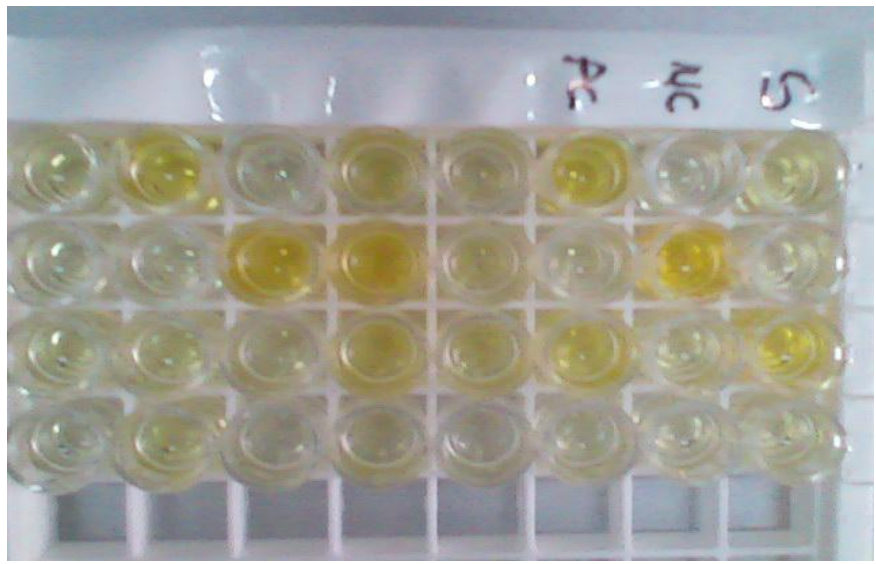

5c. Results

\section{Inclusion Criteria}

\begin{tabular}{|l|l|}
\hline $\begin{array}{l}\text { a.Morning } \\
\text { stiffness }\end{array}$ & $\begin{array}{l}\text { Stiffness in and around the joints lasting 1 hr before maximal } \\
\text { improvement }\end{array}$ \\
\hline $\begin{array}{l}\text { b.Arthritis of } \\
\text { three or }>\text { joint } \\
\text { areas }\end{array}$ & $\begin{array}{l}\text { At least 3 joint areas simultaneously have had soft tissue swelling or } \\
\text { fluid (proximal interphalangeal, metacarpo phalangeal, wrist, elbow, } \\
\text { knee, ankle, and metatarso phalangeal joints) }\end{array}$ \\
\hline $\begin{array}{l}\text { c.Arthritis of } \\
\text { hand joints }\end{array}$ & $\begin{array}{l}\text { Arthritis of wrist, metacarpo phalangeal joint, or proximal } \\
\text { interphalangeal joint. }\end{array}$ \\
\hline $\begin{array}{l}\text { d.Symmetric } \\
\text { arthritis }\end{array}$ & $\begin{array}{l}\text { Simultaneous involvement of the same joint areas on both sides of the } \\
\text { body. }\end{array}$ \\
\hline $\begin{array}{l}\text { e.Rheumatoid } \\
\text { nodules }\end{array}$ & $\begin{array}{l}\text { Subcutaneous nodules over bony prominences, extensor surfaces, or } \\
\text { juxtaarticular regions observed by a physician }\end{array}$ \\
\hline f.Serum RF & Positive serum Rheumatoid Factor \\
\hline $\begin{array}{l}\text { g.Radiographic } \\
\text { changes }\end{array}$ & $\begin{array}{l}\text { Typical changes of RA on postero anterior hand and wrist radiographs } \\
\text { that must include erosions or unequivocal bony decalcification localized } \\
\text { in or most marked adjacent to the involved joints. }\end{array}$ \\
\hline
\end{tabular}




\section{Interpretation of results}

\begin{tabular}{|l|l|}
\hline \multicolumn{1}{|c|}{ Interpretation } & \multicolumn{1}{c|}{ Observation } \\
\hline Distinct coarse agglutination & Within $0.5 \mathrm{mts}$ - strong positive \\
\hline Fine agglutination & After full $2 \mathrm{mts}$ - weak positive \\
\hline Smooth suspension & Negative \\
\hline
\end{tabular}

\section{Anti-CCP or RF Positive (any one +ve)}

In the present study (88\%) which is higher than the study by Bizzaro et al., ${ }^{5}$ who reported $31.6 \%$ positivity in RA patients (Table 1 ).

\section{Specificity of both Anti CCP \& RF}

The present study results were similar with the study by Sibel Altun et al., ${ }^{5}$ who showed $98.6 \%$ for both tests positive in combination.

\section{Anti CCP in CTD (SLE)}

In CTD including SLE only (4\%) which is similar to the study by Sibel Altun et al., (4\%).In an another study by Medivake et al., ${ }^{5}$ (1.2\%). Ulrich sauer land ${ }^{24}$ and a recent article by Gottenberg et al., ${ }^{24}$ also confirmed the lesser prevalance of anti CCP in SLE.

In a study by RDL ${ }^{10} 9.7 \%$., In contrast $\mathrm{O}$ Kasapcopur et al., ${ }^{28}$ study showed absence of anti-CCP antibody which is also not in agreement with the present study.

The indifference might have overcome if the study was carried with large sample size, and for a period of long duration.

\section{RF in SLE}

Likewise in the present study with SLE- RF was positive in $(22 \%)$ which goes in parallel with the study by Sibel Altun et al., ${ }^{5}-20 \%$ positivity. This indicates that anti-CCP antibody assay can be a useful indicator in differentiating SLE from RA than RF test.

\section{Other Arthritis (OA) and HBD}

The present study results showed none of the OA and Healthy Blood Donors had positive Anti-CCP values which is in positive correlation with the study by Sibel Altun et al., 5 .

Another study by Nehir Samanci et al., 11 showed $(1.2 \%)$ which is not in consistent with the present study. Absence of anti CCP antibodies in $\mathrm{OA}$ and HBD signifies its specificity in RA and will help in excluding them from RA.

In the present study RF was positive in $(12 \%)$ OA patients and in (8\%) HBD (all were anti CCP -ve), which goes in agreement with the study by Sibel Altun et al., ${ }^{5}(10 \%)$ in OA patients and $10 \%$ in HBD. The result denotes the non-specificity of RF.

Another study by Nehir Samanci et al., ${ }^{11}$ shows $44.8 \%$ RF positivity in OA cases and $4.8 \%$ in controls which is higher than the present study. This disparity of the results could be due to age mis- matched controls and small sample size (due to categorization of subjects into many groups). An ideal control population would have been an agematched normal control population. In the present study, Anti CCP anti bodies in Rheumatoid Arthritis and other arthritis (SLE patients \&OA) patients were assessed along with healthy blood donors as control.

The anti CCP test shows high positive rate in RA patients than other arthritic disease 
patients, and negative in OA and Healthy Blood Donors. This reconfirmed the better specificity of anti CCP test in RA and thus it can be used as a diagnostic tool.

Since Anti CCP positivity is very low in SLE it helps in differentiating RA from other connective tissue disorders including SLE patients.

Anti CCP was negative in OA and HBD. So it will be useful in excluding these cases from RA.

Even though RF is equally sensitive as Anti $\mathrm{CCP}$ in RA, it is less specific when compared with Anti CCP.

\section{Limitation}

A large sample size, and a longitudinal study with periodical follow up will definitely be of greater value in prediction of anti CCP positivity.

\section{Future scope of the present study}

The study can be further extended to involve different types of kits to test their sensitivity and specificity, for better prediction. Hope further research will reveal the significance of protein citrullination in the immunopathology of RA.

The ACPA era has just begun, and is creating a revolution in Rheumatology. As per the findings of the present study AntiCCP test is more sensitive and highly specific. AntiCCP antibody is a very valuable serological indicator in diagnosis of RA.

Anti CCP has the hallmark of establishing as a diagnostic tool and provides additive sensitivity to RF. The presence of both RF and Anti CCP in serum is a strong indicator of RA.

\section{Inclusion criteria}

RA: According to the ACR (American College of Rheumatology) criteria $^{14}$ Criteria a-d must be present for at least 6weeks.To diagnose as RA any 4 should present.

\section{CTD (SLE)}

Arthritis along with vasculitis, Photosensitivity \&Malar rash

OA: Joint pain with no h/o injury or sepsis. Brief morning stiffness $(<30 \mathrm{mts})$

Localised pain aggravated by use \&relieved by rest. No symmetrical involvement of joints.

\section{Healthy blood donors}

Healthy persons without any infection, or any communicable diseases.

\section{Exclusion criteria}

RA: If does not fit in to the ACR criteria.

CTD: Bony deformity without vasculitis.

OA: Joint pain with h/o injury or sepsis \& Joint pain at rest.

HBD: Persons with any infection, or communicable diseases.

\section{Acknowledgement}

I express my sincere gratitude to our honourable Dean, Thanjavur Medical College, Thanjavur, Associate Professor, professor and Head of the Department of Microbiology, faculties of Orthopaedic \&Rheumatology department for their encouragement and valuable suggestions to carry out my study success fully. My special 
thanks to all the subjects who were involved in this study for their kind co-operation to carry out this study. I also thank my family members. Finally I thank The Almighty for His blessings in every moment in my life.

\section{References}

1. Gerard A. Schellekens, Ben A.W. de Jong, Frank H.J. van den Hoogen et al.Citrulline is an Essential Constituent of Antigenic Determinants Rheumatoid Arthritis-specific Autoantibodies. January 1998; Volume101(Number 1):273 -281.

2. Thomas Skogh.Does a positive anti-CCP test identify a distinct arthritis entity?Arthritis Research \&Therapy, December 2005; Vol 7 (No 6) : 121.

3. Kunihiro Nishimura, MD,MPH; MS; Daisuke Sugiyama, MD, MPH Yoshinori Kogata et al. Annals of Internal Medicine Meta-analysis: Diagnostic Accuracy of Anti-Cyclic Citrullinated Peptide Antibody and Rheumatoid Factor for Rheumatoid Arthritis. American College of Physicians, 2007; 146: 797-808.

4. Eric-jan j. A.Kroot,ben a.W.De jong et al.The prognostic value of Anti-cyclic citrullinated peptide antibody in patients with recent - onset Rheumatoid arthritis \& Rheumatism. August 2000; vol. 43 no. 8: pp 1831-1835.

5. S.bel altun,Reyhan calipkan,y.Al.oner et al.a new marker in Rheumatoid Arthritis- autoimmunity relation: anticyclic citrullinated peptide antibody. Turk j immunol; 2004; 9: 21-265.

6. Pooja khosla,s Shankar,lalit duggal et al. Anti ccp antibodies in rheumatoid Arthritis. Rheumatol assoc.2004; $12: 143$ - 46.

7. Martinus AM van Boekel, R Vossenaar,Frank HJ van den Hoogen et al. autoantibody systems in rheumatoid arthritis: Specificity, sensitivity and diagnostic value Arthritis. Res, 2002; 4:87-93.

8. Gerard a.Schellekens, hendrik visser,ben a.W.De jong et al. The diagnostic properties of rheumatoid arthritis antibodies recognizing a cyclic citrullinated peptide. Arthritis \& Rheumatism,2000; vol. 43,no.1: pp 155156.

9. By Anil Vasishta, Diagnosing early-onset rheumatoid Arthritis: The role of antiCCP antibodies, American clinical laboratory. Aug-Sep - 2002;

10. RDLCyclic Citrullinated Peptide,CCP: A New Serum Markers for Rheumatoid Arthritis, Updated September 4; 2007.

11. Nehir samanci, md. sebahat ozdem, md; Halide akbas, et al. Diagnostic value and clinical significance of anti-ccp in patients with Advanced rheumatoid arthritis. journal national medical association, August, 2005;(vol.97) no. 8:

12. vanAken,J.H.M.vanBilsen,C.F. Allaart, T.W.J. Huizinga, F.C.Breedveld et al.The Leiden Early Arthritis Clinic,Clin Exp Rheumatol 2003; 21 (Sup31): S100S105.

13. FA van Gaalen,SP Linn-Rasker,WJ van Venrooij et al. Autoantibodies predict progression to Rheumatoid arthritis in undifferentiated arthritis. The Netherlands Arthritis Res Ther, 2003; 5( suppl1):28.

14. S.L.E.Ribeiro H.L.A. Pereira,N.P. Silva,et al. Anti-cyclic citrullinated peptide antibodies and rheumatoid factor in leprosy patients with articular involvement. Braz J Med Biol 2008; Res 41.

15. The American Association for Clinical Chemistry. Papers in Press doi: 10.2004; 1373/ clinche

16. A.J.W.Zendman,W.J.vanVenrooij and G.J.M. Pruijn et al,Use and significance of anti-CCP autoantibodies in rheumatoid arthritis. Rheumatology; 2006, 45:20-25. 
17. Ger J.M. Pruijn,Erik R.Vossenaar,Jan WDrijfhout, Walther J. van Venrooij et al.Anti-CCP Antibody Detection Facilitates Early Diagnosis and Prognosis of Rheumatoid Arthritis. Current RheumatologyReviews, 2005;1, 1-7 1.

18. Very early'Rheumatoid'arthritis cohorts: limited by selection, Oxford University Press on behalf of the British Society for Rheumatology; 2006.

19. K.P.Machold1,V.P.K. Nell1,T.A.Stamm et al,The Austrian Early Arthritis Registry.Clin Exp Rheumatol; 2003, 21 (Suppl. 31): S113 - S117.

20. Anti - citrullinated protein antibody, Wikipedia.

21. CT Chou1HT Liao2,CH Chen et al,The Clinical Application of Anti- CCP in Rheumatoid Arthritis and Other Rheumatic Diseases Biomarker Insights: $2007 ; 2$ :165 - 171 .
22. NancyA.Shadick,MD,MPH;NancyR.Coo k,ScD;ElizabethW.Karlson,MD; et al,C - reactive Protein in the Prediction of Rheumatoid Arthritis in Women. Arch Intern Med. 2006; 166 : 2490-2494.

23. The Predictive Power of Anti-Cyclic Citrullinated Peptide Antibodies: Window into Understanding Gene / Environment / Immunity Interactions, 2006, The Journal of Rheumatology; 33:7.

24. Ulrich sauerland, heidemarie Becker, matthias seidel et al. Clinical utility of the anti-CCP assay experiences with 700 patients Ann. N.Y. acad. Sci. 2005; 1050: 314-318.

25. Münevver serdarofluhaoim çakârbay orhan defer et al, the association of anti-ccp antibodies with disease activity in rheumatoid arthritis.Rheumatol int, 2008 ; 28: 965-970.

\section{How to cite this article:}

Ayisha, D., Eunice Swarna Jacob and Shanmugapriya, P. 2017. Comparison of Anti CCP Positivity in RA and Other Arthritic Patients Including Connective Tissue Disorders. Int.J.Curr.Microbiol.App.Sci. 6(10): 2461-2473. doi: https://doi.org/10.20546/ijcmas.2017.610.291 